\title{
The Change of Educational Processes, Learning and Teaching in Engineering Education
}

\author{
Carlos Efren Mora-Luis ${ }^{1 *}$, Jorge Martin-Gutierrez ${ }^{2}$ \\ ${ }^{1}$ Assistant Professor, Polytechnic School of Engineering, Universidad de La Laguna, SPAIN \\ ${ }^{2}$ Associate Professor, Faculty of Engineering and Technology, Universidad de La Laguna, SPAIN
}

Educating engineers towards facing global challenges is a key aspect of higher education today. Universities around the World are assuming this challenge by adopting student-centred learning strategies to reach the needs of newer generations. Active learning is more than just using newer teaching methods or recent pedagogies: it requires a solid understanding of the needs of the learning processes and the learning community to prepare students for global change and sustainable development goals and challenges. Thus, active learning is more than just facing problems from one specific discipline.

Today, there is more technology and advances, but more complexity. Higher education institutions must transfer several skills to prepare its engineering students to assume newer technological challenges but, at the same time, newer engineers should consider social needs as part of the equation. In this regard, active learning models such as Problem Based Learning and its variations have become quite popular at all educational levels to prepare students for real-world problems, and concepts like social issues are becoming quite common in Engineering Education. However, adopting these models is not a straightforward process as it requires deep institutional changes affecting not just students and academic staff, but also its administration and its infrastructures, and its relationship with society.

The modernisation process of Engineering Education and the evolution of our society create new global difficulties in educating engineers. The demand of science, technology, engineering, and mathematics (STEM) professionals is high and, at the same time, there is more emphasis on transdisciplinary, hybrid skills, and sustainable development goals. Unfortunately, the interest of students for engineering is decreasing in many countries, and the presence of women is low when compared to other disciplines. Challenging students to addressing social and environmental issues could increase their interest on engineering, but students' perceptions of STEM are not necessarily aligned with global challenges. As a consequence, students do not usually think of STEM professions to be linked with jobs associated with sustainability and social issues. Thus, making engineering more attractive, widening its social perception, and reducing the gender gap are three main challenges of Engineering Education.

Educational institutions and researchers should explore Engineering Education challenges by investigating what motivates the students to become engineers. Developing core STEM skills and transversal skills (e.g. creativity, problem-solving, communication of ideas) during early educational stages is one of the goals of educational researchers to improve engineering attractiveness. Keeping students motivated after they decided becoming engineers is also a relevant aspect to improve students' perception of engineering.

This Special Issue, The Change of Educational Processes, Learning and Teaching in Engineering Education, contains a paper presenting the experience of Professor Kewalramani and her team to developing STEM skills at an early age. They performed their research with early childhood teachers and children by using of internetconnected toys (IoToys) to understand possibilities for developing children's cognitive capacities (e.g., creativity, inquiry, engineering design thinking). Prof. Kewalramani and her team obtained a valuable result after using modern learning methods with 5 to 6 years old children to develop STEM engagement. In a second paper, professor Subheesh and Dr. Sethy explored the importance of providing feedback to engineering students. They discussed the need for specific pedagogical training for engineering faculty members, despite it is not a requirement when joining an engineering education institution. Prof. Subheesh and Dr. Sethy explored the relevance of qualitative feedback during assessment and the principles of a good feedback practice. Their recommendations on assessment and feedback represent good practices to improve students' perception of their educational process to becoming engineers.

\section{http://www.ejmste.com}

(c) 2020 by the authors; licensee Modestum Ltd., UK. This article is an open access article distributed under the terms and conditions of the Creative Commons Attribution License (http://creativecommons.org/licenses/by/4.0/). $\square$ carmora@ull.edu.es (*Correspondence) $\square$ jmargu@ull.edu.es 